\title{
Formação de leitores literários mediada pelo software educacional HagáQuê: uma proposta para leitura de conto
}

\author{
Ana Paula Teixeira Porto* \\ Daiane Samara Wildner Ott"
}

\section{Resumo}

Diante de um contexto cercado pela tecnologia, em que a atenção com os livros concorre com a dada a aparelhos tecnológicos, e marcado pelo declínio do número de leitores no Brasil, propõe-se a utilização o software educacional HagáQuê como recurso no processo de mediação de leitura literária, uma prática que não se quer extinta apesar dos diversos dados que apontam para seu apagamento em bancos escolares. O objetivo deste trabalho é apresentar uma proposta de ensino que explora a interatividade para despertar o interesse do aluno pelo contato com o texto literário, para isso foi escolhido o conto A caolha, de Júlia Lopes de Almeida, destacando a temática da relação entre pais e filhos. Além, parte-se de pressupostos acerca da formação de leitores e do ensino de literatura. O estudo mostra que o centro das aulas de Literatura deve ser o texto literário, criando espaço para reflexão sobre temáticas que envolvem a sociedade e levando o aluno à sensibilização e ao pensamento crítico, o que se opõe aos métodos tradicionais de ensino. O uso do HagáQuê revela-se como um eficiente suporte para a interação do aluno com o texto literário, oportunizando a criação de uma história apoiada na leitura e reflexão sobre o conto.

Palavras-chave: Leitura. Literatura. Interação. HagáQuê.
* Doutora e mestre em Letras. Pesquisadora e docente do Mestrado em Letras - Literatura Comparada da Universidade Regional Integrada (URI) - campus de Frederico Westphalen, RS. E-mail: anapaula@uri.edu.br

** Mestranda do Programa de Pós-Graduação - Mestrado em Letras - Literatura Comparada, da URI, campus de Frederico Westphalen. Docente da Escola Estadual de Ensino Fundamental Bento Gonçalves e do Colégio Nossa Senhora Auxiliadora. E-mail: daiane_wildner@ hotmail.com

Data de submissão: set. 2015 - Data de aceite: nov. 2015 http://dx.doi.org/10.5335/rdes.v11i2.5386 


\section{Introdução}

A formação de leitores literários, críticos e atuantes na sociedade brasileira faz parte dos objetivos de professores durante todo o processo educativo, especialmente, nas últimas décadas nas quais exames avaliativos comprovam que os índices de leitura no Brasil decaíram significativamente ${ }^{1}$ e que a leitura perdeu espaço para os aparelhos digitais. Cada vez mais, o estudante é atraído pela tecnologia e as ferramentas que ela lhe proporciona, investindo grande parte de seu tempo em redes sociais, jogos e outras distrações.

Essa afirmação pode ser comprovada pelos dados disponíveis em Retratos da Leitura no Brasil 3, organizado por Failla (2012), os quais revelam que $85 \%$ das pessoas preferem assistir à tevê, enquanto que $52 \%$ ouvem música durante seu tempo livre. A leitura nessa perspectiva aparece em sétimo lugar, com apenas $28 \%$ da preferência. Nota-se que as pessoas, em geral, preferem outras atividades à leitura e que a tecnologia tem dominado o espaço de tempo livre no decorrer do dia.

É preciso lembrar, também, que alunos de ensino fundamental são, em sua maioria, "nativos digitais" e, portanto, já nasceram cercados pela tecnologia. Para eles, é comum usar aparelhos e ferramentas tecnológicos em suas atividades rotineiras, o que torna esses aparatos indispensáveis até para tarefas mais simples, como para manter contato com os amigos. De uma forma ou outra, o aluno está sempre em constante interação com seus amigos, por meio de jogos, redes sociais, ou ele interage sozinho com os aplicativos e ferramentas disponibilizados pelos aparelhos tecnológicos.

Durante as aulas, por muitas vezes, essa interação é minimizada, e o aluno torna-se apenas ouvinte. $\mathrm{O}$ ambiente da sala de aula é diferente do ambiente virtual em que o aluno está habituado, as aulas geralmente são expositivas e não interativas, o professor, por muitas vezes não sabe lidar com o novo perfil de aluno. Este, por sua vez, não tem grande interesse em metodologias não interativas e que não exploram $o$ universo que lhe é familiar, o universo tecnológico. Assim, entende-se que esse período na escola precisaria oportunizar momentos de maior envolvimento por parte dos alunos na aprendizagem e ao mesmo tempo ampliar as possibilidades de ensino e aprendizagem que sejam mais condizentes com as peculiaridades que os discentes apresentam.

Considerando esse contexto, este trabalho oferece uma proposta de mediação de leitura que se utiliza de tecnologias, especialmente do software educacional HagáQuê (HQ), para mediar a leitura literária com o objetivo de investir na formação de leitores de literatura no primeiro ano do ensino médio. Para desenvolver este estudo, tomam-se como suporte para o desenvolvimento de aulas interativas o software HagáQuê, que é um programa desenvolvido para a cria- 
ção de histórias em quadrinhos e possibilita o desenvolvimento da criatividade e autonomia do aluno, utilizando-se da escrita de histórias.

O HagáQuê é uma ferramenta que auxilia o desenvolvimento das habilidades de leitura e síntese, relacionando a literatura com a linguagem visual e fornecendo meios para crescimento da criatividade do aluno em práticas de escrita de textos. Assim, a proposta é focar as habilidades de leitura e escrita, indo além da capacidade de escrita já oportunizada pelo software HagáQuê. Além disso, o fato de o software não utilizar a internet durante sua execução, somente é necessária a internet para baixar o programa, permite a sua exploração em escolas que não disponibilizam de uma rede de internet com grande capacidade.

\section{Contexto atual sobre a leitura e o ensino de Literatura no Brasil}

De acordo com as informações oferecidas pelas pesquisas em Retratos da Leitura no Brasil 3 (2012), houve uma queda significativa nos hábitos de leitura dos brasileiros: a última pesquisa releva que o número de pessoas que se dizem leitores é de 88,2 milhões, ou seja, apenas $50 \%$ da população, são 7,4 milhões de leitores a menos do na pesquisa anterior, em 2007.

O estudo Retratos da Leitura no Brasil 3 (2012) mostra ainda que os alunos leitores, em sua maioria, têm lido revistas, jornais ou livros indicados pela escola. Além disso, o uso dos livros em papel tem perdido espaço para os e-books - livros digitais. Esses dados mostram que o trabalho de resgate da leitura deve ser intenso e que o uso dos computadores tornou-se cada vez mais comum, tendo que se pensar no computador como um aliado do ensino.

Outras pesquisas também reforçam a queda de leitores no Brasil. Nesse sentido, destaca-se o levantamento do Pisa $2012,{ }^{3}$ que mostra que o país somou 410 pontos em leitura, revelando uma queda de dois pontos em relação à última pesquisa, em 2009. Esses dados, se comparados aos de outros países, mostram-se mais preocupantes, pois o país está na $55^{\mathrm{a}}$ posição no ranking de leitura dentre os 65 países participantes. Além disso, no que diz respeito aos seis níveis de leitura, quase a metade dos estudantes brasileiros não chegaram ao nível 2, correspondente ao nível de inferência de informações básicas do texto, como reconhecimento da ideia principal do texto ou de partes desse texto, assim como reflexões em que haja comparação entre o texto e seus conhecimentos sobre 0 assunto.

Há outros resultados que exprimem a fragilidade no ensino decorrente da falta do hábito de ler e escrever, como mostra o Exame Nacional de Ensino Médio (Enem) de 2014. Sobre isso, a repórter Mariana Tokarnia (2015) divulga que 529.374 pessoas zeraram a redação, enquanto que apenas 250 tiraram a nota máxima. A notícia expõe a opinião de 
especialistas, que afirmam que os alunos não conseguem ao menos seguir a temática proposta, dentre outros problemas de redação. Isso também é resultado, para eles, de falta de práticas leitoras e escritas.

Esses dados anunciam que é preciso incentivar o hábito de leitura e escrita, podendo até mesmo usar a tecnologia como uma ferramenta de disseminação da literatura, além de produção e divulgação de textos criados pelos alunos. Para isso, é importante que a tecnologia não seja vista como um meio de combate ao livro e aos leitores, como se pensava no final do século XX. Pelo contrário, hoje, a internet tem se tornado um meio de propagação dos textos literários, ganhando pela agilidade em relação ao texto impresso. Sirlene Cristófano, ao se referir ao pensamento que havia no século XX, explica que:

Era nítido que essas pessoas não percebiam o que estava realmente acontecendo em nível tecnológico, não compreendiam ainda o valor e a contribuição de tais recursos. Mas, existiam também pessoas que percebiam as vantagens proporcionadas pelas novas tecnologias, como por exemplo, aquelas utilizadas à edição de obras, com a utilização do revisor de textos, o acesso à compra rápida de livros, pois podemos encomendá-los através da Internet (2010, p. 7-8, grifo do autor).

Tem-se aqui uma visão a favor da internet e dos recursos tecnológicos oferecidos pelo computador, mostrando que eles podem ajudar a divulgar as obras literárias e não substituí-las. Neste ambiente de leitura, é importante entender qual é sua função e sobre isso Santos e Silva afirmam que "A leitura vai muito além do simples fato de encontrar o sentido literal de palavras dentro de um texto" e é isso que diferencia os leitores de meros decodificadores de palavras, tornando-se leitores ativos. Também explicam que "Ler é um processo no qual o leitor participa ativamente, buscando e atribuindo sentido ao que foi escrito por outra pessoa" (SANTOS; SILVA, 2013, p. 2).

Os autores continuam sua discussão, abordando o fato de a leitura despertar no homem sua capacidade inquiridora - de investigação, de busca constante -, que é a capacidade essencial para a formação de opinião própria e da consciência no ato de exigir direitos e no de exercer deveres. Em consonância com essa visão, Bragato, citada por Santos e Silva expressa a ideia de que a leitura é vista como fonte de conhecimento sobre diferentes visões de mundo e o leitor consegue, nesta visão mais ampla, rever seus conceitos e opiniões. E ainda há outra visão sobre a leitura sustentada pela autora: a de que ler é um processo histórico, pois, por meio dos textos, tem-se acesso a variados conhecimentos no âmbito da cultura, política e economia de uma sociedade (BRAGATO, 2005 apud SANTOS; SILVA, 2013).

Nesse contexto, é importante perceber a importância da leitura para a formação integral e crítica do ser, tornando-o atuante no espaço literário. E o mais essencial é que se procurem meios para que os leitores, em nossos tempos, tenham acesso ao livro ou mes- 
mo ao texto literário, incluindo nessa divulgação os meios eletrônicos, já que têm apresentado facilidade e rapidez na propagação de textos.

Regina Zilberman é uma das pesquisadoras contemporâneas que se destaca pela preocupação na formação de leitores no Brasil, inquietando-se com o ensino de literatura que não prioriza a leitura literária, mas aspectos relacionados à história e à memorização de conceitos e datas. Zilberman (2005) revela sua posição contrária a um ensino de literatura focado na história e no período literário em que a obra está inserida. Para mudar esse foco, defende a ideia de um ensino calcado no estudo das obras, partindo de um gênero ou de uma temática a ser estudada. A autora mostra, assim como Cereja (2005), que o sistema de ensino atual está fundamentado na perspectiva histórica e isso vem da cultura portuguesa, que nos trouxe sua forma de ensino-aprendizagem e a incorporou nas escolas brasileiras.

Zilberman (2005) afirma que desde então a forma arcaica de ensinar literatura permanece em nossas universidades e é, por isso, que o professor não sabe ensinar literatura de forma diferente. A autora caracteriza o ensino de literatura no Brasil da seguinte forma: ensino fundamentado na perspectiva histórica e tomado de forma cronológica para estudar a evolução de cada período literário, fazendo um aluno pensar que um período literário é superior a outro. $\mathrm{E}$ ainda, na divisão das literaturas por nacionalidades, isolando a literatura brasileira da portuguesa e até mesmo da africana; criando um sentimento de oposição e marginalização com as literaturas oriundas de Portugal ou da África.

Cereja (2005) também constrói reflexões acerca de ensinar e aprender literatura no mundo contemporâneo; suas considerações baseiam-se na Lei $\mathrm{n}^{\circ}$ $5.692 / 1971$ para uma avaliação ${ }^{4}$ da metodologia usada em sala de aula. De acordo com suas pesquisas, o autor identifica que o ensino de literatura, geralmente, é programado de duas formas. A primeira é a utilização de conceitos básicos que posteriormente servirão de base para 0 entendimento do texto e dos fatores linguísticos ligados a ele. A segunda, após o aprendizado dos conceitos básicos, inicia-se com o estudo da literatura por épocas, refazendo uma análise histórica e identificando as características que marcaram a escrita em cada movimento literário.

Além disso, ao se pensar em literatura nas escolas, percebe-se uma predominância do uso da literatura brasileira apenas, esquecendo-se das literaturas lusófonas em geral, que, além da língua, tiveram grandes semelhanças com a literatura na evolução e na história. Outro aspecto que influencia a base curricular das aulas de Literatura, segundo Cereja (2005), é o vínculo existente entre o conteúdo do vestibular e o conteúdo das aulas e, por muitas vezes, o vestibular utiliza-se de questões que envolvem a fixação de conceitos, datas, nomes, preconizando a memorização e não a 
investigação dos significados e possíveis reflexões que o texto pode sugerir.

Quanto à metodologia usada pela maioria dos professores, nota-se a uniformidade em apresentar os conceitos, a história e o período literário quase sempre de forma oral, e assim introduzir a leitura do texto literário. As questões elaboradas limitam-se àquelas relacionadas aos conceitos, e não ao texto. Diante dessas constatações, Cereja conclui que:

Como se vê, o texto, que deveria ser o centro das atividades de uma aula de literatura, espaço para a negociação de diferentes leituras e construções de sentido, geralmente acaba por assumir um papel periférico quanto a essas possibilidades (2005, p. 57).

Cereja constata uma consolidação do ensino de literatura sob a perspectiva histórica, tradição que se solidificou em mais de um século de caminhada e que excluía as possibilidades do ensino sob o olhar social diante da análise de textos, já que a interpretação dos textos não era o foco das aulas. Com o passar dos anos, essa metodologia passou a ser contestada principalmente no meio acadêmico, porém, o maior obstáculo encontrado é aprender a ensinar literatura quando os professores não conseguem identificar outra técnica a não ser a historiográfica. É o que Cereja aponta no trecho a seguir:

Amparada pelo contexto positivista da época e pela própria legislação vigente, a historiografia literária tornou-se nesse período a única referência para inúmeras gerações de professores, que aprenderam e ensinaram literatura a partir desse tipo de abordagem, sem sequer pensar na possibilidade de existência de outras abordagens (2005, p. 125).
Diante dessas considerações, é possível observar que, mesmo o professor identificando falhas no ensino de literatura, também encontra dificuldades em fazer mudanças em suas práticas didáticas, pois as formas de ensino utilizadas, em sua maioria, acabam remontando à maneira histórica e de memorização de datas e características que marcaram um período literário.

Jaime Ginzburg (2012) identifica como um motivo da impossibilidade de mudar essa forma de trabalho com a literatura o fato de o seu ensino ser regido pelas provas de vestibulares, que, por muitas vezes, baseiam-se apenas em questões relacionadas a datas, a períodos literários e conhecimentos acerca de quais escritores se destacaram em cada época. Dessa forma, o autor caracteriza o ensino de literatura como instrumental, ou seja, como uma função pré-definida, que seria ensinar para a obtenção de uma nota boa em provas e vestibulares.

$\mathrm{O}$ autor percebe as mesmas dificuldades apontadas por Cereja (2005). Ginzburg (2012) defende a ideia de que a literatura deve ser ensinada com qualidade, e para isso o autor cita como importantes os seguintes aspectos durante as aulas: reflexão crítica, leitura de textos dos mais diversificados gêneros, estímulo da capacidade de síntese, análise e correlação com outras obras.

Ana Paula Teixeira Porto e Luana Teixeira Porto (2014) também discutem sobre o ensino de literatura nos dias atuais e apontam que, em geral, ele segue a 
tradição literária priorizando obras canônicas que são consideradas importantes na seleção de textos escolhidos pelos professores. Alertam ainda que muitas práticas utilizam-se da fragmentação de obras para a análise, o que simplifica ou até mesmo impossibilita a análise e a interpretação do texto. Essas práticas podem tornar-se uma forma de desmotivar a leitura literária, tornando-a cada vez mais distante do aluno. As autoras reforçam, ainda, que o aluno precisa desenvolver a capacidade de relacionar obras, estimulando a pesquisa e o diálogo com outras áreas.

É possível perceber que esse é um dos motivos que tem tornado as aulas de literatura desinteressantes, e até mesmo um fracasso. Seus objetivos mínimos não têm sido alcançados e o resultado é um desestímulo para parte dos alunos e professores. Cereja (2005) define essa situação como um "discurso didático sobre literatura" que tem sido promovido primeiro pelo professor e depois pelo livro didático, pela forma com que as universidades disponibilizam seus programas, pelos vestibulares e, enfim, pelos meios de pesquisas que também caracterizam a literatura dessa forma.

Outra dificuldade enfrentada refere-se à indicação de obras literárias pelos professores: geralmente, as obras escolhidas seguem a lista de obras e autores canônicos que norteiam as exigências do vestibular, tirando possibilidades diversas de leitura e interação com os textos literários que contemplam o per- fil do leitor e excluindo a possibilidade de leituras estrangeiras, por exemplo. Além de tudo, a exigência de leituras é desestimulante e gera preocupações nos alunos, como a necessidade de ler obras de Machado de Assis para poder "tirar uma nota boa" no vestibular. Essas preocupações acabam mudando o objetivo primordial da leitura, que é ler para a formação integral do ser, despertar o conhecimento, a sensibilidade e a formação do aluno. Tudo isso também pode influenciar o gosto pelo contato com o texto literário, já que a leitura torna-se obrigatória e restrita a textos antigos, autores canônicos e a uma linguagem que muitas vezes não é adequada à realidade do aluno.

O que se nota nos professores, por sua vez, é que suas práticas pedagógicas já estão arraigadas a velhos costumes e que é difícil se pensar em outros métodos de se ensinar literatura, principalmente pelo fato de a cobrança maior ser feita pela sociedade em geral, que requer um bom desempenho nas seleções para as universidades. $\mathrm{O}$ que se espera, então, é uma mudança em toda a forma de se pensar o ensino e as qualificações que se espera de um aluno, um conhecimento memorizado, que logo pode ser esquecido, ou um conhecimento construído pela reflexão e pela crítica, despertando o interesse pela leitura e por suas nuances.

Para isso, pensa-se em incluir ao ensino de literatura o uso de ferramentas tecnológicas, já que as tecnologias têm se tornado cada vez mais presentes em 
casas, empresas, escolas e em todos os ambientes sociais. Segundo pesquisa realizada pelo E-Commerce Brasil em 2014, o Brasil é o terceiro país no mundo que passa mais tempo na internet. Os dados mostram ainda que $54 \%$ da população brasileira são usuários ativos da internet, e o mais impressionante é que há mais celulares do que habitantes no país, sendo esse instrumento um veículo importantíssimo para a difusão de práticas relacionadas à internet, de acordo com o apontado no estudo (E-COMMERCE, 2015).

Mas o acesso facilitado a recursos tecnológicos garante uma formação de leitores? Erika Macedo (2013) preocupa-se com a questão da formação de leitores nesse contexto e mostra que esse processo continua sendo uma discussão no ambiente escolar. Mesmo em uma "sociedade midiática", assim caracterizada pela autora, há que se pensar na leitura como uma das formas de aprendizado e, ainda, que se considerarem as diferenças nas formas de recepção e como isso influencia o leitor. Hoje, encontram-se muito mais receptores passivos do que analíticos, afirma a autora. Isso implica em uma reconfiguração das propostas pedagógicas, em que se fundamentem aspectos críticos, inclusive utilizando-se das tecnologias da informação e comunicação para transpor as barreiras do acesso a esse público que tem ganhado espaço no meio digital e voz para manifestar sua opinião, mesmo que muitas vezes desorientados e ferindo aspectos morais do outro. Esse último merece ponto de destaque da parte dos professores, sendo a escola um local de formação cidadã do indivíduo como um todo, torna-se necessário a inclusão dos suportes tecnológicos e o estudo dos aspectos relacionados à produção e à divulgação de textos nesse ambiente.

Outra questão que tem ganhado destaque nesses novos tempos é a interatividade que se inicia na fase infantil, por meio de brincadeiras, jogos, e permanece na fase da adolescência em redes sociais, jogos, entre outros usos, e se estende até a fase da juventude e adulta, podendo ser observada em diversas atividades, como programas que tem como foco a aprendizagem, o uso de redes sociais, os programas de rádio e TV, quando fazem apelo aos telespectadores ou ouvintes. Hoje existem muitos cursos on-line que se utilizam de métodos interativos e cada vez mais esse fenômeno tem ganhado espaço. Macedo alerta que o fenômeno da interatividade tem trazido mudanças na cultura. E, nesse sentido, a cultura que é parte integrante na formação humana e nas relações sociais toma-se como um fundamento a ser observado para as relações concernentes ao ensino:

O leitor dos tempos hodiernos é cercado pela interatividade, considerada por teóricos contemporâneos como um dos mais importantes fenômenos de transformação cultural. Esse fenômeno redefine o próprio conceito de cultura, possibilitando a concepção do multiculturalismo (2013, p. 1). 
Essas ideias destacam a interatividade como indispensável na formação de leitores, já que cada ambiente social é carregado de valores culturais próprios de sua comunidade. Torna-se importante a inclusão dos ambientes virtuais e de dispositivos eletrônicos e da mídia em práticas de ensino, fazendo aproximação com novas realidades que integram a vida dos alunos, e ainda, oportunizando a discussão sobre esses diferentes locais, alterações na forma de comunicação e também familiarização ou inserção dos valores culturais que cada ambiente propicia. No entanto, é preciso reconhecer que, mesmo em tempos em que as relações sociais, por meio das ferramentas tecnológicas, encontram-se tão avançadas e dinâmicas, ainda existem aqueles que não participam ou estão totalmente excluídos delas.

A ideia de inclusão dessa nova cultura alerta para que o foco seja o sujeito leitor e sua relação com o texto e não para questionamentos de ordem exclusivamente estética. Este tempo, em que as mudanças na comunicação e nas relações sociais têm se tornado incisivas, compreende também transformações na recepção do texto: "As tecnologias digitais afetam estruturalmente a produção dos sentidos devido ao modo como os textos são elaborados e intercambiados" (MACEDO, 2013, p. 2). É caso, por exemplo, dos hipertextos, diante dos quais o leitor é que projeta a ordem e a sequência de sua leitura, construindo assim, a interpretação. E é nesse momento que se torna necessária a intervenção de alguém
- diga-se, do professor -, no processo de mediação do ensino, norteando, assim, as leituras e a construção da aprendizagem.

Dulce Melão (2010) explica como tem se fortalecido a concepção de mediação e sua relevância nas práticas de ensino, o que traz mudanças também no âmbito da comunicação, que hoje pode designar-se comunicação em rede e ainda na relação estabelecida com a língua portuguesa. Diante disso, outra questão importante se acentua em nosso contexto atual: as relações entre comunicação e educação. A autora defende então que deve haver colaboração de todos os envolvidos no processo educativo, as mudanças não cabem somente à escola, e o caminho é readequação de práticas de ensino para uma educação tecnológica.

Nessa linha de raciocínio, o filósofo Francês Roger Chartier afirma que:

Além de auxiliar no aprendizado, a tecnologia faz circular os textos de forma intensa, aberta e universal e, acredito, vai criar um novo tipo de obra literária ou histórica (ZAHAR, 2007, não paginado).

Intensa porque a todo o momento estão sendo incluídos milhares de textos em suportes digitais, muitos deles de fácil acesso a qualquer um. Abertas, pois todos têm acesso a esses textos e de forma fácil, rápida e sem custo. E por fim, universal porque se refere à variedade de textos, veiculados em todas os idiomas e, assim, alcançando todos os povos.

É importante nesse contexto tecnológico entender que houve muitas transformações na leitura do mundo e, por isso, é necessário incluir, no processo 
de leitura de texto, o texto em formato digital em ações de aprendizagem literária: "o contacto com o livro, a motivação para a leitura e as estratégias guiadas para a sua aprendizagem constituem um mosaico de saberes que terá também de espelhar o mundo digital, instaurando, porventura, novas vias no imaginário infantil" (MELÃO, 2010, p. 5).

Diante das reflexões aqui apresentas, concernentes à formação de leitores literários em um contexto cercado pela tecnologia, constrói-se a próxima seção que trará explicações sobre o conceito de software educacional, caracterizações do software HagáQuê e em que sentido esse recurso pode auxiliar na formação de leitores literários, considerando que em nossos dias os alunos são, em sua maioria, nativos digitais.

\section{Contribuições do software educacional HagáQuê para a formação de leitores literários}

Em busca de ferramentas tecnológicas que visem auxiliar a formação intelectual das crianças, colaborando com o crescimento educacional em todos os ambientes de aprendizagem, já que o computador se faz presente em grande parte desses espaços, pensou-se no uso dos softwares educacionais como colaboradores no processo de formação de leitores. Pereira (2008) acentua que esses softwares podem ensinar de forma lúdica, retomando ideias já conhecidas no âmbito educacional.

Para exploração desse recurso, o professor precisa conhecer e saber usar o software, investigando quais são suas potencialidades e limitações e investindo naquilo de bom que o programa lhe oferece. Dentre as possibilidades dos softwares associados ao ensino, salientam-se: proporcionar experiências que se utilizem dos sentidos para se aproximar do real, induzir o aluno à reflexão e à tomada de decisões, facilitar a aprendizagem, desenvolver a identidade do aluno, melhorar as habilidades linguísticas e desenvolver a criticidade no aluno. E pelo fato de serem características comuns à aprendizagem, revelam-se como primordiais a um bom software educativo.

Diante dessas características, o software pode ser considerado uma ferramenta apta ao uso nas mais variadas áreas do conhecimento, pois inclui habilidades e saberes interdisciplinares e colabora para a aproximação do aluno. $\mathrm{O}$ fato de o software unir muitos conhecimentos a um contexto que seja familiar ao aluno também o aproxima da realidade e torna $o$ aprendizado mais significativo.

Após essas reflexões, que consideram o software educacional como uma ferramenta que visa à construção de conhecimentos pelos alunos e que, portanto, deve oferecer recursos que possibilitem criar e construir seus próprios conceitos, analisa-se o software HagáQuê, sua funcionalidade em relação ao objetivo dessa 
proposta, com o intuito de diagnosticar em que sentido ele pode ser útil para a análise crítica de textos literários, foco deste trabalho.

A ferramenta HagáQuê é um programa desenvolvido pela Unicamp e tem como objetivo facilitar a criação de histórias em quadrinhos, além disso, busca promover as aulas, pois se trata da criação de histórias e do aprendizado das habilidades que envolvem os meios digitais. Segundo informações contidas no tutorial do $\mathrm{HQ}$, o programa: "Foi desenvolvido de modo a facilitar o processo de criação de uma história em quadrinhos por uma criança ainda inexperiente no uso do computador, mas com recursos suficientes para não limitar sua imaginação" (TUTORIALDO HQ, [2011?], p. 1),

$\mathrm{O}$ uso desse recurso tecnológico foi escolhido para a criação e o desenvolvimento de aulas criativas, pois é um software que propicia tanto ao aluno quanto ao professor um contato interativo e lúdico durante as atividades de produção textual. Pensando que a habilidade de escrita deve ser incentivada de forma que o aluno sinta-se não somente cobrado, mas como um real autor, que possua um objetivo e um público a quem destinar seu texto, propõe-se a criação de histórias em quadrinhos por meio de um programa especializado.

O programa retoma a ideia de história em quadrinhos conhecida pelos alunos, é uma forma divertida de contar histórias, misturando imagens e recursos linguísticos para representar as falas e os sons e com a vantagem de, por ser um programa, ser apresentado aos colegas na tela interativa e proporcionar a todos o uso de sons, o que reforça ainda mais o sentido atribuído ao texto. Além disso, "O programa é intuitivo e fácil de manipular" (TUTORIALDO HQ, [2011?], p. 1). Ou seja, mesmo que o aluno não tenha muitos conhecimentos sobre o uso de softwares, ele consegue facilmente entender como usar as ações oferecidas.

O programa é de fácil acesso, podendo ser baixado gratuitamente no site da Unicamp, no endereço eletrônico <http:// www.nied.unicamp.br/?q=content/ hag\%C3\%A1qu\%C3\%AA>. Após baixado e aberto, já na tela inicial, abrem-se os espaços próprios para os quadrinhos e abrirá automaticamente uma caixa com as figuras, em que o aluno poderá, utilizando-se dos recursos disponibilizados no próprio programa, produzir o cenário, incluir personagens e falas, criando o enredo da história. O programa disponibiliza ao criador da história opções de cenário e de balões de fala, pensamento, narrador, entre outros recursos. Além de fornecer figuras e sons, possibilita acesso direto do programa à internet e aos arquivos do computador para pesquisa de imagens, sons ou até mesmo para a criação desses.

Depois de pronta, a história pode ser salva, aberta, impressa e até mesmo publicada na internet e todas essas ações podem ser feitas nesse mesmo menu. Durante o processo de criação das histórias, o aluno pode editar imagens, recorrer a 
alguns recursos, como aumentar e diminuir o tamanho das figuras, girar, mudar a posição da foto, transferir a imagens para trás do balão de fala ou de outras imagens, enfim, fazer as adaptações necessárias para a criação do texto. É um ótimo meio para usar a criatividade e despertar o interesse pela aprendizagem eletrônica e discursiva.

O software HagáQuê, assim como as histórias em quadrinhos, oportuniza a leitura dinâmica, permite relacionar imagem e escrita, usando recursos, como onomatopeias, balões de fala, nos quais a linguagem é informal e natural, caracterizando o personagem. Pode-se definir esse programa como um meio de interação que serve como instrumento de entretenimento, diversão e fonte para despertar a criatividade do aluno e a criação de histórias que o auxiliem na compreensão textual por meio das linguagens visual e escrita. O HagáQuê também pode ser usado para a análise e síntese de conteúdos das mais diversas áreas do conhecimento, tornando-o não somente fonte para a produção de textos, e sim para o aprendizado efetivo por meio da reflexão feita pelo aluno durante a composição de sua história.

Diante dessas qualidades atribuídas a esse programa, pode-se compreender seu caráter pedagógico, por facilitar a interação dos alunos, o interesse à escrita, à pesquisa, à criatividade e ao desenvolvimento de habilidades eletrônicas, inclusive, pelo fato de ser um programa que todos podem utilizar, até mesmo aqueles que não têm um conhecimento tão grande sobre o uso de computadores.

Sobre sua capacidade auxiliadora de práticas leitoras, partindo de uma atividade lúdica, Bim, citado por Zancanaro (2011), explica que o Hagáquê parte de uma atividade lúdica para a transmissão de conhecimentos, auxiliando no desenvolvimento cognitivo, afetivo e psicomotor das crianças. Ou seja, o software não se utiliza apenas da criatividade da criança, mas por meio dela produz novos conhecimentos, fazendo relações com a área afetiva, psicológica e motora (2001 apud Zancanaro, 2011).

Zancanaro (2011) explora ainda mais o uso desse programa, ao refletir sobre seu estímulo à língua falada e à escrita, relacionando esse programa não apenas a disciplinas de língua portuguesa e redação, mas incluindo todas as áreas do conhecimento na produção e síntese de textos:

Por ser um software aberto, com uma interface acessível e atraente, permite um trabalho agradável, através da exploração de temas multidisciplinares, podendo contribuir para o acesso ao conhecimento sistematizado e também incentivar os alunos à leitura, e por consequência, a produção escrita (ZANCANARO, 2011, p. 27).

As histórias em quadrinhos são um meio importante de leitura e escrita, pois despertam no leitor conhecimentos linguísticos e culturais, como o uso de gírias, de expressões em situações informais, em que o diálogo se aproxima daquele observado em situações vividas no cotidiano pela criança. Por isso, são 
de fundamental importância para o aprendizado e o envolvimento do aluno. As imagens também fornecem subsídio para a internalização das histórias e o consequente aprendizado.

Com as ideias apresentadas por Bim, é possível perceber que esse programa fornece os meios necessários para o envolvimento do aluno com o texto, despertando nele o interesse para a prática da escrita, e mais, desvela sua criatividade e criticidade, já que aproxima o aluno de práticas comuns ao seu dia a dia e usa de formas lúdicas para estimular a transmissão de conhecimentos.

Da mesma forma, mas agora com base nas ideias de Alonso e Santarosa (2006), Zancanaro (2011) explica que a leitura envolve processos cognitivos e atividades socioculturais: a leitura constitui-se no instrumento que permite o acesso à cultura e ao conhecimento, enquanto a escrita constrói o pensamento lógico, organizando e estruturando a informação que gera o conhecimento.

Constata-se, com essas proposições, que a atividade de escrita exige mais conhecimentos da criança do que a leitura apenas, porém não se pode deixar de notar que ambos são atos dependentes um do outro e que ambos devem ser exercitados. Diante disso, encontra-se no HagáQuê uma ferramenta que auxilia essas habilidades, dando suporte para o desenvolvimento da criatividade do autor, que, em contato com o texto, pode usar seus conhecimentos, sua cultura e suas vivências para criar novas histórias.
Hawad (1994), apud Bim, Tanaka e Rocha ([2000?]) também traz informações sobre a contribuição das histórias em quadrinhos na produção textual infantil, já que são textos que aportam momentos e falas informais, aspecto que leva à identificação, pela criança, com o texto escrito, por lhe ser comum, usual. E diante dessa familiaridade, apreende-se que as habilidades despertadas pelos recursos utilizados pelas histórias em quadrinhos são de grande valia para as atividades pedagógicas.

Todas essas características citadas sobre o uso das histórias em quadrinhos e sobre o HagáQuê reforçam a ideia inicial de se pensar em meios que contribuam efetivamente para o bom andamento das aulas de leitura e escrita, tendo-se como princípio a interação do aluno, o aprendizado eficiente e o gosto pelo contato com textos literários. Partindo disso, criou-se uma proposta de leitura literária, utilizando-se o HagáQuê como ferramenta profícua para a leitura literária crítica. Essa proposta é desenvolvida na próxima seção.

\section{Leitura do conto A caolha sob o olhar do relacionamento entre pais e filhos}

A proposta de mediação literária com o uso do software HagáQuê é formulada considerando-se os pressupostos acima arrolados, nas seções 2 e 3. Toma-se como 
objeto central o texto literário, a partir do qual se apresenta uma prática de leitura literária. Para fins de organização dessa prática, há uma sequência orientadora, que esclarece o que se propõe, como se propõe realizar a mediação e por quais razões. Destaca-se ainda que essa proposta leva em conta orientações da matriz de referência do Enem, já que a mediação é redirecionada ao ensino médio.

Para leitura do conto com essa prática, apresentam-se: pressupostos, objetivos, habilidades e competências, metodologia, público-alvo, roteiro de atividades e avaliação.

\section{Pressupostos}

A leitura do conto A caolha, de Júlia Lopes Almeida, é requisito básico para o desenvolvimento dessa proposta. $\mathrm{O}$ conto se insere na literatura brasileira do século XX, podendo ser analisado sob diversos focos. Esta proposta apresenta a temática relacionamento entre pais e filhos, pensando que esse é um assunto que merece destaque e discussão em sala de aula, constituindo-se, então, um dos motivos da escolha do conto. De outro modo, há que se pensar que a literatura de Júlia Lopes Almeida, autora que não se apresenta no rol dos autores canônicos, apresenta temáticas polêmicas para a época, e que se enquadra nos problemas sociais vividos no presente momento.

A partir da leitura desse conto, busca-se a reflexão sobre a relação entre pais e filhos e estimula-se um diálogo com situações atuais, de mesmo assunto. Estuda-se, ainda, a relação entre a temática e os diferentes contextos, virada do século XIX e XX e o contexto atual. Júlia Lopes Neto destacou-se como escritora em sua época, principalmente pelo fato, de ser a primeira escritora mulher a viver da literatura. Suas obras resgataram valores e princípios de vida, mostrando variedade em temas. Em uma época marcada pela urbanização da sociedade e pela produção em massa, Júlia defendia ideais femininos, o trabalho remunerado e questões de ordem educacional por intermédio da literatura.

A escolha do conto A caolha, criado por uma escritora que não é reconhecida no rol da literatura canônica, tem como intuito valorizar obras não consagradas pela crítica literária, mas que merecem destaque em sala de aula por constituir de obras igualmente ricas em temáticas sociais, apresentando marcas do contexto social em que o texto foi publicado e oferecendo base para a reflexão crítica. Dessa forma, a proposta norteia-se na ideia, defendida por Zilberman (1984), de que as práticas literárias em sala de aula devem ser desenvolvidas privilegiando-se a promoção de habilidades específicas nos alunos, e não apenas norteadas pelas leituras canônicas. Além disso, a autora destaca que não se deve desprezar textos não consagrados.

Questões relacionadas ao contexto de produção, livro em que foi publicado o conto e ano de publicação também são necessários para o desenvolvimento da 
aula. Parte-se da leitura literária para a análise da temática proposta, desenvolvendo reflexões coesas e consistentes a respeito do texto. Deve-se lembrar de que a literatura traz contribuições importantes para a construção social do indivíduo e da coletividade, conforme estudos desenvolvidos no primeiro capítulo e fundamentados Colomer (2007).

Assim com essa proposição, pressupõem-se os seguintes conhecimentos já citados e embasados na primeira proposta: conhecimento do gênero conto e sua função discursiva, noções de literatura comparada, conhecimentos sobre a função social da literatura, ênfase na leitura literária para refletir sobre a sociedade e, por fim, conhecimento sobre o software HagáQuê e como utilizá-lo. Caberá à escola fornecer computadores, que devem conter o recurso tecnológico já instalado. Ainda, é necessário conhecer o gênero fanfiction $^{5}$ e as possibilidades de uso que ele oferece para releitura de textos. Nesse caso, com implementação da fanfiction, a proposta será fazer a leitura do conto até certo ponto, propondo ao aluno a criação de uma fanfiction, utilizando o software HagáQuê, para dar um final para a história. Somente depois dessa produção será revelado o final do conto.

\section{Objetivos}

\section{Objetivo geral}

Potencializar estratégias de leitura literária por meio do recurso tecnológico HagáQuê, fazendo o aluno refletir sobre o texto, o contexto de produção e sua relação com a realidade.

\section{Objetivos específicos}

Contribuir para a reflexão sobre $o$ relacionamento entre pais e filhos a partir da leitura literária, reconhecendo a função humanizadora do texto literário e relacionando ficção com realidade.

Promover a leitura do texto literário, introduzindo conhecimentos relacionados ao assunto, autor e contexto social e cultural de criação da obra literária a fim de despertar mais interesse à leitura de textos de mesmo autor.

Instigar o aluno ao desenvolvimento de habilidades relacionadas à escrita a partir do software educacional HagáQuê, imbricando interatividade ao processo de produção textual e leitura crítica do texto literário.

Articulando-se aos objetivos da proposição, ainda é possível eleger habilidades que são indicadas na matriz de referência do Enem (2012), como:

H12 - Reconhecer diferentes funções da arte, do trabalho da produção dos artistas em seus meios culturais.

H15 - Estabelecer relações entre o texto literário e o momento de sua produção, situando aspectos do contexto histórico, social e político.

H17 - Reconhecer a presença de valores sociais e humanos atualizáveis e permanentes no patrimônio literário nacional.

H18 - Identificar os elementos que concorrem para a progressão temática 
e para a organização e estruturação de textos de diferentes gêneros e tipos.

H21 - Reconhecer em textos de diferentes gêneros, recursos verbais e não-verbais utilizados com a finalidade de criar e mudar comportamentos e hábitos.

H26 - Relacionar as variedades linguísticas a situações específicas de uso social.

H28 - Reconhecer a função e o impacto social das diferentes tecnologias da comunicação e informação.

\section{Público-alvo}

A atividade proposta destina-se a alunos do primeiro ano do ensino médio, considerando os mesmos argumentos defendidos na primeira proposta.

\section{Metodologia}

Utilizando-se de métodos interativos, esta proposta procura mediar ações de leitura literária e reflexão crítica, além da produção de uma fanfiction, que procura desenvolver a autonomia do aluno e incitá-lo a refletir sobre questões de ordem social, bem como em soluções para seus problemas.

Os recursos necessários para o desenvolvimento da aula são de ordem humana, material e tecnológica. É inegável a participação do professor para mediar as ações durante a aula, constituindo o recurso humano, juntamente com os alunos, sujeitos essenciais do processo de formação de leitores literários. De ordem material é necessário cópia impressa do conto para a leitura, revistas (uma para cada aluno) para seleção de imagens para a atividade inicial. Já o recurso tecnológico requisitado são computadores com o software HagáQuê.

O tempo estimado para a realização da proposta é de cinco aulas de 50 minutos, podendo haver variações de acordo com cada turma.

As atividades aqui propostas utilizam-se de uma variedade de recursos, que vão de material impresso, ao uso de revistas a até recursos tecnológicos, como o software HagáQuê, com o intuito de acrescentar atividades interativas às aulas de literatura sem desmerecer as atividades escritas também necessárias ao desenvolvimento do aluno.

Os seguintes materiais são indicados para a leitura prévia do professor, pois também se acredita que a mediação de leitura deve incorporar um trabalho de leitura do docente, que deve englobar, além do próprio texto literário explorado, referências críticas sobre ele:

- Conto A caolha, de Júlia Lopes de Almeida. In: ALMEIDA, Julia Lopes de. Ansia Eterna. Rio de janeiro: H. Garnier,1903. Disponível em: <http:// www.biblio.com.br/conteudo/JuliaLopesdeAlmeida/AnsiaEterna/acaolha/ moldura.asp>.

- Artigo Tradição e vanguarda na escritura de Júlia Lopes de Almeida, de Maria Beatriz Zanchet. Disponível em: <e-revista.unioeste. br/index.php/trama/article/downlo$\mathrm{ad} / 677 / 570>$. 
- Artigo Ansia eterna: desdobramentos do insólito na narrativa de Júlia Lopes de Almeida, escrito por Viviane Arena Figueiredo. Disponível em: <http://www.abralic.org.br/eventos/ cong2011/AnaisOnline/resumos/ TC0908-1.pdf>.

\section{Roteiro de leitura (sequência didática)}

O Quadro 1 foi elaborado com a finalidade de colaborar com a sequência didática, dividindo-a em atividades e delimitando o tempo estimado.

Quadro 1 - Sequência da aula

\begin{tabular}{|c|c|c|}
\hline $\begin{array}{c}\text { Atividades/ } \\
\text { passo a passo da aula }\end{array}$ & Exposição do que será realizado & Aula \\
\hline 1 - Motivação & $\begin{array}{l}\text { Distribuição de revistas para a seleção de uma } \\
\text { imagem que identifique o relacionamento do aluno } \\
\text { com os pais. Após isso, o aluno explica por que } \\
\text { escolheu determinada imagem. }\end{array}$ & 1 \\
\hline $\begin{array}{l}2 \text { - Mobilização para a leitura e } \\
\text { introdução de informações sobre } \\
\text { o autor e o contexto social. }\end{array}$ & $\begin{array}{l}\text { Questões que despertem o interesse do aluno } \\
\text { pela leitura do conto, expondo informações sobre } \\
\text { o autor e o contexto social em que foi criado. }\end{array}$ & 1 \\
\hline $\begin{array}{l}\text { 3- Leitura e atividades sobre o } \\
\text { conto A caolha, de Júlia Lopes } \\
\text { de Almeida. }\end{array}$ & $\begin{array}{l}\text { Leitura oral do conto e análise dos aspectos } \\
\text { sociais tratados na narrativa. Discussão sobre a } \\
\text { temática relacionamento entre pais e filhos. }\end{array}$ & 2 \\
\hline 4 - Produção textual & $\begin{array}{l}\text { Produção de uma fanfiction, utilizando o software } \\
\text { HagáQuê. }\end{array}$ & 3 \\
\hline 5 - Criação do livro & $\begin{array}{l}\text { Avaliação e correção dos textos para publicação } \\
\text { em livro da turma. }\end{array}$ & 4 \\
\hline $\begin{array}{l}6 \text { - Exposição das fanfictions e } \\
\text { atividades escritas. }\end{array}$ & $\begin{array}{l}\text { Exposição dos textos em forma de livro, em que } \\
\text { cada aluno explica aos colegas como imaginou } \\
\text { o final da história. Após a exposição, o final do } \\
\text { conto será lido e serão feitas atividades escritas } \\
\text { para análise mais detalhada do tema proposto. }\end{array}$ & 5 \\
\hline
\end{tabular}




\section{Atividade 1}

Distribuição de revistas aos alunos, pedindo que cada um escolha uma imagem que caracterize e resuma seu relacionamento com os pais. A imagem não precisa ser de uma família, mas de algo que lembre a relação do aluno com os pais. Exemplo: a imagem de uma corrente com vários elos pode simbolizar a ligação, a confiança entre ambas as partes. Após a escolha da imagem, cada aluno deve explicar, por meio de uma frase curta, por que escolheu aquela imagem. O objetivo dessa atividade é mobilizar o aluno para a reflexão do tema proposto, aproximando o texto literário da realidade do aluno.

\section{Atividade 2}

Neste momento, uma cópia do o conto A caolha será entregue a cada um dos alunos e antes da leitura serão feitas as seguintes perguntas:

1) A partir do título do conto, que fatos você imagina que serão relatados?

2) Que temática social você imagina ser tratada neste conto?

3) Alguém já ouviu falar em Júlia Lopes Neto? Já leram textos dessa autora?

Após a exposição das sugestões feitas pelos alunos, o professor poderá aproveitar para contextualizar sobre a autora, a época em que viveu, introduzindo o contexto histórico em que o conto foi publicado. Com essa abordagem, o pro- fessor estará aproximando o aluno do contexto de produção do texto.

\section{Atividade 3}

Após a exposição sobre a autora e o contexto histórico em que a obra foi escrita, inicia-se a leitura coletiva do texto, promovendo-se a leitura oral e incentivando-se a participação de todos os alunos. Durante a leitura, o professor pode fazer pausas, questionando os alunos a respeito do enredo, dos personagens, do narrador e tecendo comentários sobre as relações sociais apresentadas na história. Dessa forma, as seguintes questões servem como referência para este momento:

Roteiro oral:

1) De que forma a imagem da mulher é construída no início do conto?

2) Como pode ser classificado o narrador da história? Explique.

3) Que reação você imagina ter ao ver esta mulher?

4) Da forma como o menino age com a mãe, parece demonstrar-lhe afeto?

5) Qual a posição da sociedade em relação ao menino e à mãe?

6) Você considera essa posição discriminatória? Justifique.

7) A relação do menino com a mãe sofre variações ao longo da história. O que isso indica sobre o menino?

8) Explique de que forma a temática do relacionamento entre pais e filhos está presente neste conto.

9) O que você acha que levou a mulher a ficar caolha? 
10) Em sua opinião, por que ela não revela isso ao menino?

O final da história só deve ser disponibilizado ao aluno durante a atividade 5. Então, a leitura do conto deve ser finalizada no seguinte trecho:

"A madrinha escutou-o comovida; depois disse:

- Eu previa isso mesmo, quando aconselhava tua mãe a que te dissesse a verdade inteira; ela não quis, aí está!

- Que verdade, madrinha?" (ALMEIDA, 1903).

Após a leitura até esse excerto, propõe-se que os alunos sejam instigados a pensar em como teria acabado a história: qual seria essa verdade ainda oculta? O que essa mãe tanto esconde do filho? $\mathrm{E}$ por que ela teria feito isso? Eles apenas devem refletir sobre tais questões, levantando possíveis hipóteses, mas sem revelar aos colegas o que cada um pensa.

\section{Atividade 4}

\section{Produção textual}

Nesta fase, os alunos deverão interagir com a parte do conto lido e a história em quadrinhos que serão convidados a construir de forma a oportunizar uma aproximação entre leitura literária e reflexão. Os alunos produzirão um desfecho para a história com base nas duas últimas questões da atividade 3. Para isso, eles devem usar o software HagáQuê, elaborando uma fanfiction. Se os alunos ainda não conhecem esse gênero textual, cabe ao professor explicar-lhes.
Segue a proposta para a produção do texto: Utilizando-se do recurso HagáQuê produza uma fanfiction que narre a parte inicial do conto e também revele sua previsão sobre o final da história. Para isso, você deve imaginar as características físicas e psicológicas dos personagens e construí-las na sua $\mathrm{HQ}$ com a imagem dos personagens, de suas falas e de suas ações. Seu texto deve ser coerente com sua leitura do conto original, por isso, utilize o máximo de informações disponibilizadas no conto para criar o cenário, os personagens e o desfecho da história. A sua criatividade está sendo desafiada, especialmente quando pensar no final para essa história.

\section{Atividade 5}

Após a criação das fanfictions, os textos devem ser impressos e reunidos em um livro da turma para que seja feita uma exposição oral e visual em sala de aula. Cada aluno terá um tempo para explicar sobre o final que criou para a história da caolha, expondo sua visão sobre a personagem, argumentando sobre o motivo de ter escolhido esse final. Todos passarão por esse mesmo processo.

Somente depois da exposição é que o professor fará a distribuição do trecho final do conto. Esse trecho pode ser lido pelo professor ou, ainda, ele pode escolher apenas um aluno para a leitura, dessa forma, os alunos darão mais atenção ao final da história. Quando a leitura for concluída, poderão ser explorados mais detalhadamente os aspectos 
sobre a relação entre pais e filhos, de forma a estabelecer um diálogo entre o contexto de produção do conto com o contexto atual. Para isso, segue o roteiro de atividades a seguir:

\section{Roteiro escrito}

1) O final do conto revela-se surpreendente, porque:

I) O leitor não imagina que o final da história teria o menino como vilão.

II) Choca o leitor ao apresentar a figura de uma mãe protetora, que em todo momento escondeu a verdade para não magoar o filho.

III) A figura da mãe é apresentada como uma mulher gentil, mas mentirosa.

IV) O menino queria saber a verdade, mas é confrontado quando a verdade lhe é apresentada.

2) Assinale a resposta que apresenta todas as afirmações verdadeiras a respeito da história.
a) I e II.
b) I, III e IV.
c) II, III e IV
d) II e IV.
e) Nenhuma das afirmações é verda- deira.

3) A imagem da caolha, apresentada pelo narrador no início do conto, é desconstruída no final da história. Isso revela uma questão bastante comentada na sociedade e que pode ser traduzida pelo seguinte provérbio popular:
a) Quem com ferro fere, com ferro será ferido.
b) Não há rosas sem espinhos.
c) Quem vê cara não vê coração.
d) Quem tudo quer, nada tem.
e) Filho de peixe, peixinho é.

4) Explique de que forma a relação entre mãe e filho é abordada no conto, identificando os valores humanos da mãe e do filho.

5) Que críticas à sociedade da virada do XIX e XX são apresentadas por meio desse conto?

6) Argumente sobre como esse conto pode aproximar-se da nossa realidade. Utilize-se de exemplos revelados por intermédio da mídia para comprovar suas afirmações.

7) Analisando as assertivas abaixo, qual delas apresenta uma leitura INADEQUADA sobre o conto:

a) Neste conto, a figura de mãe é construída por meio de características físicas e psicológicas que revelam uma entrega total ao filho e à família, anulando a si mesma.

b) A desconstrução da beleza feminina mostra que as mulheres, naquela época, não valorizavam seu físico, apenas manifestavam preocupação com a casa e filhos. 
c) À medida que o menino vai crescendo, sua relação de afeto em relação à mãe começa a diminuir, e por um momento, ele trata a mãe com o mesmo repúdio que a sociedade tinha sobre ela.

d) O sentimento expresso pela figura da mãe, transfigura uma idealização do sentimento materno, negando-se a si mesma e assumindo uma posição de culpa pela fatalidade acontecida.

e) O trabalho realizado por Júlia Lopes de Almeida releva-se complexo no âmbito familiar, podendo atestar a figura materna dominante na época e ainda apresentar reflexões a respeito do sentimento de gratidão de filho para os pais.

\section{Avaliação}

Com o intuito de avaliar o desempenho do aluno em todos os objetivos elencados nesta proposta, a avaliação deve ser feita durante cada momento da aula, observando a participação dos alunos nas atividades de ordem oral, escrita, produção do texto até a exposição dos textos em livro efetivado pela turma e explicação de suas fanfictions.

\section{Considerações finais}

Apresentada a proposta de mediação de leitura literária com o uso do HagáQuê, destaca-se como potencialidade do recurso o fato de o aluno poder fazer uma leitura de texto literário de forma prazerosa, utilizando-se de imagens que permitem visualizar o cenário, os personagens e, assim, facilitar o entendimento da história literária problematizada. O enredo também é traçado de forma diferente, analisando além das falas, as imagens que compõem a história. Por outro modo, o software HagáQuê oferece apenas a criação de gêneros textuais que envolvem quadrinhos, como tirinha, charge, história em quadrinhos e fanfiction.

Se, por um lado, o recurso oferece um número limitado de gêneros para a produção dos textos, por outro, ele serve como suporte para avaliar os alunos em relação às suas leituras a respeito de um texto literário, como o conto A caolha, certamente pouco explorado e até mesmo nem conhecido no contexto escolar. Isso porque o desenvolvimento da história, das falas e das ações revela a posição do aluno frente ao assunto tratado, e a caracterização dos personagens e do cenário conduz ao desenvolvimento de competências referentes à leitura coerente do texto literário explorado como objeto central da mediação de leitura.

Essa proposta, além de não priorizar o texto literário canônico nem relacioná-lo a escolas literárias, já que a proposta de leitura partiu de um tema, procura intensificar interativas de leitura que promovam a interação do aluno com o texto literário. Para isso, utilizou-se um recurso tecnológico, mostrando que é importante haver atualizações nas práticas de ensino sem cair em um tradicional e 
superado modelo de texto-leitura-exercícios. Entende-se que, dessa forma, a formação do leitor pode ser otimizada com inovações metodológicas que incluem $o$ uso de recursos tecnológicos para atrair o aluno para a leitura e análise do texto.

Já que os alunos são, em sua maioria, nativos digitais (sem desconsiderar o fato de que muitos não o são), pensou-se em aulas que proporcionassem a eles a mesma interação que há em suas práticas cotidianas, tornando as aulas de literatura prazerosas, porém não menos reflexivas. Macedo (2013) destaca a importância de promover ações de aprendizagem de leitura crítica em sala de aula, principalmente porque, diante do contexto midiático, encontram-se mais sujeitos passivos do que analíticos. Assim, a autora vê a possibilidade de usar as tecnologias para alcançar os alunos e aposta em propostas pedagógicas que incitem à leitura de forma crítica.

Ainda, na proposição dessa mediação de leitura do conto de Júlia Lopes de Almeida, procurou-se priorizar a prática social da literatura, destacada por Candido (2002) e Malard (1985). Candido afirma que o contato com o texto literário é indispensável ao homem, pois atua na formação da sua humanidade. Malard também defende o ensino de literatura por meio da leitura literária, tendo a visão de literatura como prática social de interação e formação do ser humano. Diante disso, buscou-se estimular a leitura do texto literário com práticas e reflexões que pudessem ajudar o aluno a refletir sobre sua realidade, aguçando o discente à reflexão da função social da literatura.

Acredita-se que a proposta de mediação de leitura é não apenas uma forma de incitar a leitura literária sem incorrer em antigos métodos e possibilidades já desgastadas, mas especialmente sinaliza para uma possibilidade viável de ensino da literatura nas escolas e especialmente de gosto pela leitura literária. Nesse sentido, entende-se que o software é uma ferramenta que pode assumir um papel importante nesse processo: o de possibilitar maior interação do aluno com o objeto de leitura - no caso o conto, e, também, o de aproximar o ensino da realidade do século XXI, fazendo com que a escola e suas práticas sejam de fato condizentes com a atualidade.

\section{Formation of literary readers mediated by the educational software HagáQuê: a proposal for literary reading}

\section{Abstract}

Faced with a context surrounded by technology, in that the attention to the books rivals that given the technological devices, and marked by the decline of the readership in Brazil, it proposes to use educational software HagáQuê as a resource in the mediation to the literary reading, a practice that does not want herself extinct, despite the various data related to their deletion in benches school. The objective of this paper is to present a proposal for a school that to explo- 
res the interactivity to awaken student interest in the contact with the literary text, for this, we choose the short story A caolha, by Júlia Lopes de Almeida, highlighting the theme of the relationship between parents and children. In addition, one starts with assumptions about the formation of readers and of the literature teaching. The study shows that the center of Literature classes should be the literary text, creating space for reflection on issues involving society and leading the student to awareness and critical thinking, which is opposed to the traditional teaching methods. The use of HagáQuê proves to be an efficient support for student interaction with the literary text, providing opportunities to create a story based in reading and reflection on the tale.

Keywords: Reading. Literature. Interaction. HagáQuê.

\section{Notas}

1 Segundo os dados obtidos na pesquisa Retratos do Brasil 3 (2012) houve no Brasil uma diminuição ainda maior na leitura nos últimos anos, sendo leitores apenas $50 \%$ da população. Registrou-se uma queda de 7,4 milhões de leitores desde 2007 até 2012.

2 Segundo Prenski (2001), a expressão "nativos digitais" designa os nascidos no meio digital, envolvidos por computadores, internet, celulares, e enfim toda a gama de aparelhos que permitem a informação rápida e o múltiplo processamento de informações. O que também faz com a tecnologia lhes seja familiar e presente em sua vida diária.

3 O Programa Internacional de Avaliação de Alunos (Pisa) tem como finalidade coletar dados sobre o ensino que contribuam para a discussão e a melhoria da educação para os países participantes. As avaliações são feitas nas seguintes áreas do conhecimento: Matemática, Leitura e Ciências.
4 Com a institucionalização desta lei, Cereja (2005) explica que houve a necessidade de instrumentalizar os professores, até mesmo despreparados diante da carência existente, sendo necessária a utilização de livros didáticos em sala de aula, o que tirou de certa forma a autonomia do professor e ignorou sua competência em desenvolver seus próprios métodos de ensino, universalizando-os.

5 O gênero fanfiction trata de criação de histórias feitas por fãs, sem fins lucrativos, sem ferir os direitos autorais, mas, sim, ampliando seu contato com a obra que aprecia. O escritor parte de obras feitas por terceiros - cinema, televisão ou literatura podem servir como contextos para a escolha da obra- e a partir dela oferece uma proposta criativa. A fanfiction pode explorar características de personagens que chamam a atenção, alterar desfechos ou acontecimentos, entre outros desenvolvimentos.

\section{Referências}

ALMEIDA, Julia Lopes de. Ansia eterna. Rio de Janeiro: Livreiro editor, 1903. Disponível em: <http://www.biblio.com.br/conteudo/ JuliaLopesdeAlmeida/AnsiaEterna/acaolha/ moldura.asp>. Acesso em: 25 jul. 2015.

BIM, Sílvia Amélia; TANAKA, Eduardo Hideki; ROCHA, Heloísa Vieira. HagáQuê editor de histórias em quadrinhos. [2000?]. Disponível em: <http://www.ufrgs.br/niee/ eventos/SBC/2000/pdf/wie/art_condensados/ wie060.pdf>. Acesso em: 26 nov. 2014.

. Ministério da Educação. Matriz de Referência do Enem. Brasília: Instituto Nacional de Estudos e Pesquisas Educacionais, 2012. Disponível em: <http://download. inep.gov.br/educacao_basica/enem/downloads/2012/matriz_referencia_enem.pdf $>$. Acesso em: 22 jul. 2015.

CANDIDO, Antonio. Textos de intervenção. Seleção, apresentações e notas de Vinicius Dantas. São Paulo: Duas Cidades; Editora 34, 2002.

CEREJA, William Roberto. Ensino de literatura: uma proposta dialógica para o trabalho com literatura. São Paulo: Atual, 2005. 
CRISTÓFANO, Sirlene. A literatura e as novas tecnologias: a formação de leitores ativos em múltiplos suportes. Revista Darandina, v. 3, n. 1, nov. 2010. Disponível em: <http:// www.ufjf.br/darandina/files/2010/12/A-Literatura-e-as-Novas-Tecnologias-A-Forma\%C3\%A7\%C3\%A3o-de-Leitores-Ativos-em-M\%C3\%BAltiplos-Suportes.pdf>. Acesso em: 9 out. 2014.

COLOMER, Teresa. Andar entre livros: a leitura literária na escola. Tradução de Laura Sandroni. São Paulo: Global, 2007.

E-COMMERCEBRASIL. Pesquisa mostra dados da internet no Brasil em 2015. Disponível em: <https://www.ecommercebrasil. com.br/noticias/pesquisa-mostra-dados-da-internet-no-brasil-em-2015/>. Acesso em: 23 jul. 2015.

FAILLA, Zoara (Org.). Retratos da Leitura no Brasil 3. 2012. Disponível em: http://www. imprensaoficial.com.br/retratosdaleitura/RetratosDaLeituraNoBrasil3-2012.pdf. Acesso em: 9 out. 2014 .

FIGUEIREDO. Viviane Arena. Ânsia eterna: desdobramentos do insólito na narrativa de Júlia Lopes de Almeida. CONGRESSO INTERNACIONAL DA ABRALIC, 12., Curitiba, jul. 2011. Disponível em: <http:// www.abralic.org.br/eventos/cong2011/AnaisOnline/resumos/TC0908-1.pdf>. Acesso em: 8 ago. 2015.

GINZBURG, Jaime. O ensino de literatura como fantasmagoria. Revista Anpoll, v. 1, n. 33, 2012. Disponível em: <http://www.anpoll.org.br/revista/index.php/revista/article/ view/637>. Acesso em: 26 mar. 2015.

MACEDO, Erika Bezerra Cruz de. Rodas de leitura na formação do leitor da sociedade midiática. JORNADA NACIONAL DE LITERATURA: Leituras jovens do mundo, 15., ago. 2013, Passo Fundo. Anais... Disponível em: <http://jornadasliterarias.upf.br/15jornada/ images/stories/trabalhos-12-seminario/12-erika-bezerra-cruz-de-macedo.pdf $>$. Acesso em: 12 jul. 2015.
MALARD, Letícia. Ensino de Literatura no $2^{\circ}$ grau: problemas e perspectivas. Porto Alegre: Mercado Aberto, 1985.

MELÃO. Dulce Helena M. R. Ler na era digital: os desafios da comunicação em rede e a (re)construção da(s) literacia(s). Revista Exedra, Coimbra, n. 3, p. 75-90, 2010. Disponível em: <http://www.exedrajournal.com/ docs/N3/06A-Dulce-melao_pp_75-90.pdf>. Acesso em: 12 jul. 2015.

NTM PASSO FUNDO. Tutorial do HagáQuê. [2011?]. Disponível em: <https://ntmpassofundo.files.wordpress.com/2011/07/tutorial-do-hq1.pdf>. Acesso em: 15 out. 2014.

PORTO, Ana Paula. PORTO, Luana Teixeira. A formação de leitores e livro didático: potencialidades e desafios no ensino de literatura. Revista E-scrita, Nilópolis, v. 5, n. 3, set./dez. 2014. Disponível em: <http:// www.uniabeu.edu.br/publica/index.php/RE/ article/viewFile/1524/pdf_298>. Acesso em: 21 mar. 2015.

PEREIRA, Daniervelin Renata Marques. O ensino através do computador: os tipos de softwares educativos e seu uso. Revista Texto Livre, v. 2, n. 1, 2008. Disponível em: $<$ http://www.periodicos.letras.ufmg.br/index. $\mathrm{php} /$ textolivre/article/view/14>. Acesso em: 2 fev. 2015.

PRENSKY, M. Digital natives, digital immigrants. On the Horizon. MCB University Press, v. 9, n. 5, Oct., 2001. Disponível em: <http://www.marcprensky.com/writing/ Prensky\%20-\%20Digital\%20Natives, \%20 Digital\%20Immigrants\%20-\%20Part1.pdf $>$. Acesso em: 25 set. 2014.

SANTOS, Adalgisa Félix dos; SILVA, Solimar Patriota. Iracema na rede: o uso das redes sociais para o ensino de leitura. Revista Philologus, Rio de Janeiro, n. 57, Supl.: Anais da VIII JNLFLP, Rio de Janeiro: CiFEFiL, set./dez. 2013. Disponível em: <http://www. filologia.org.br/revista/57supl/53.pdf >. Acesso em: $11 \mathrm{dez} .2014$. 
TOKARNIA, Mariana. Enem 2014: resultado mostra fragilidade na leitura e na escrita. Agência Brasil, jan. 2015. Disponível em: <http://educacao.uol.com.br/ noticias/2015/01/19/enem-2014-resultado-mostra-fragilidade-na-leitura-e-na-escrita. htm>. Acesso em: 15 jun. 2015.

ZAHAR. Cristina. Roger Chartier: Os livros resistirão às tecnologias digitais. Entrevista. 2007. Disponível em: <http://revistaescola. abril.com.br/lingua-portuguesa/fundamentos/roger-chartier-livros-resistirao-tecnologias-digitais-610077.shtml>. Acesso em: 13 jul. 2015.

ZANCANARO, Edicarla Venturolli. Avaliação do software Hagáquê, auxiliando no processo ensino-aprendizagem da língua portuguesa. Monografia (Especialização em Informática na Educação) - Universidade Aberta do Brasil, Cuiabá, 2011. Disponível em: <http://drupal.ic.ufmt.br/sites/default/files/field/pdf/Monografia/EdicarlaZancanaro. pdf>. Acesso em: 17 nov. 2014.

ZANCHET, Maria Beatriz. Tradição e vanguarda na escritura de Júlia Lopes de Almeida. Revista Trama, Marechal Cândido Rondon, v. 2, n. 4, 2006. p. 143-154. Disponível em: <e-revista.unioeste.br/index.php/ trama/article/download/677/570>. Acesso em: 8 ago. 2015.

ZILBERMAN, Regina. A leitura na escola. In:__(Org.). Leitura em crise na escola: as alternativas do professor. Porto Alegre, Mercado Aberto, 1984. p. 9-22.

. A universidade brasileira e o ensino das literaturas de língua portuguesa. In: BORDINI, Maria da Glória; REMÉDIOS, Maria Luíza Ritzel. Crítica do tempo presente: estudo, difusão e ensino de literaturas de língua portuguesa. Porto Alegre: Associação Internacional de Lusitanas, Instituto Estadual do Livro, 2005. p. 232-244. 